\title{
Application of Iterative Approaches in Modeling the Efficiency of ARIMA-GARCH Processes in the Presence of Outliers
}

\author{
Emmanuel Alphonsus Akpan ${ }^{1}$, K. E. Lasisi ${ }^{1}$, Ali Adamu², Haruna Bakari Rann ${ }^{3}$ \\ ${ }^{1}$ Department of Mathematical Science, Abubakar Tafawa Balewa University, Bauchi, Nigeria \\ ${ }^{2}$ Federal College of Education (Tech.), Gombe, Gombe State, Nigeria \\ ${ }^{3}$ Department of Mathematics and Statistics, University of Maiduguri, Maiduguri, Nigeria \\ Email: *eubong44@gmail.com
}

How to cite this paper: Akpan, E.A., Lasisi, K.E., Adamu, A. and Rann, H.B. (2019) Application of Iterative Approaches in Modeling the Efficiency of ARIMA-GARCH Processes in the Presence of Outliers. Applied Mathematics, 10, 138-158.

https://doi.org/10.4236/am.2019.103012

Received: December 24, 2018

Accepted: March 26, 2019

Published: March 29, 2019

Copyright $\odot 2019$ by author(s) and Scientific Research Publishing Inc. This work is licensed under the Creative Commons Attribution International License (CC BY 4.0).

http://creativecommons.org/licenses/by/4.0/

\begin{abstract}
The study explored both Box and Jenkins, and iterative outlier detection procedures in determining the efficiency of ARIMA-GARCH-type models in the presence of outliers using the daily closing share price returns series of four prominent banks in Nigeria (Skye (Polaris) bank, Sterling bank, Unity bank and Zenith bank) from January 3, 2006 to November 24, 2016. The series consists of 2690 observations for each bank. The data were obtained from the Nigerian Stock Exchange. Unconditional variance and kurtosis coefficient were used as criteria for measuring the efficiency of ARIMA-GARCH-type models and our findings revealed that kurtosis is a better criterion (as it is a true measure of outliers) than the unconditional variance (as it can be depleted or amplified by outliers). Specifically, the strength of this study is in showing the applicability and relevance of iterative methods in time series modeling.
\end{abstract}

\section{Keywords}

Heteroscedasticity, Kurtosis, Model Efficiency, Outliers, Unconditional Variance, Volatility

\section{Introduction}

The generalized autoregressive conditional heteroscedastic (GARCH-type) models were introduced to account for heteroscedasticity (changing variance), a phenomenon which occurs as a result of violation of assumption of constant variance in time series. The GARCH-type models are further divided into symmetric and asymmetric. The symmetric GARCH models (for example ARCH and 
GARCH) rely on modeling the conditional variance as a linear function of squared past residuals. The strength of this specification is in allowing the conditional variance to depend only on the modulus of the past variables (past positive and negative innovations have the same effect on the current conditional variance). The most interesting feature not addressed by GARCH model is the leverage effect which occurs when an unexpected drop in price (bad news) increases predictable volatility more than an unexpected increase in price (good news) of similar magnitude (Engle and Ng [1]; Francq and Zakoian [2]). The asymmetric specifications (for example EGARCH and GJR-GARCH) allow for the signs of the innovations (returns) to have impact on the volatility apart from magnitude.

Originally, the GARCH model was specified based on the normal distribution for the innovations yet could not capture the heavy-tailed characterizations. Similarly, the student-t distribution which is traditionally specified to remedy the weakness of the normal distribution in accommodating the heavy-tailed property, is found wanting in many applications to account for excess kurtosis and thus, the resulting estimates of GARCH models are not efficient (Moffat and Akpan [3]; Feng and Shi [4]).

Furthermore, previous studies have shown that the heavy-tailed property indicates the presence of excess kurtosis which in turn is a measure of outliers (Moffat and Akpan [5]; Cain, Zhang and Yuan [6]; Fiori and Beltrami [7]; Westfall [8]). Therefore, to completely account for excess kurtosis, it is required that outliers (which are the observations that deviate from the overall pattern of the distribution of the data) be adjusted for.

Hence, the aim of this study is to determine the efficiency of GARCH-type models with outliers taken into consideration using kurtosis coefficient which is at least approximately mesokurtic, and in particular seeks to improve on the work of Akpan, Lasisi and Adamu [9] who used the minimum unconditional variance (which is the standard measure of the variance of a variable) as a measure of efficiency of GARCH-type models in the presence of outliers. However, the major drawback to this approach is that, the unconditional variance pertaining to GARCH models fitted to the outlier contaminated series could be smaller than or equal to that of the outlier adjusted series against the expectation that the GARCH models fitted to outlier adjusted series would produce the minimum unconditional variance.

Moreover, the remaining part of this work is organized as follows; Section 2 takes care of materials and method then followed by results and discussion in Section 3, while the conclusion of overall results is handled in Section 4.

\section{Materials and Methods}

\subsection{Return}

The return series $R_{t}$ can be obtained given that $P_{t}$ is the price of a unit share at time, $t$ and $P_{t-1}$ is the share price at time $t-1$. 


$$
R_{t}=\nabla \ln P_{t}=(1-B) \ln P_{t}=\ln P_{t}-\ln P_{t-1}
$$

The $R_{t}$ in Equation (1) is regarded as a transformed series of the share price, $P_{t}$ meant to attain stationarity, that is, both mean and variance of the series are stable (Akpan and Moffat [9]). The letter $B$ is the backshift operator.

\subsection{Autoregressive Integrated Moving Average (ARIMA) Model}

Box, Jenkins and Reinsel [10] considered the extension of ARMA model to deal with homogenous non-stationary time series in which $X_{t}$, itself is non-stationary but its $d^{\text {th }}$ difference is a stationary ARMA model. Denoting the $d^{\text {th }}$ difference of $X_{t}$ by

$$
\varphi(B)=\phi(B) \nabla^{d} X_{t}=\theta(B) \varepsilon_{t}
$$

where $\varphi(B)$ is the nonstationary autoregressive operator such that $d$ of the roots of $\varphi(B)=0$ are unity and the remainder lie outside the unit circle. $\phi(B)$ is a stationary autoregressive operator.

\subsection{Heteroscedastic Models}

\subsubsection{Autoregressive Conditional Heteroscedastic (ARCH) Model}

The first model that provides a systematic framework for modeling heteroscedasticity is the ARCH model of Engle [11]. Specifically, an ARCH $(q)$ model assumes that,

$$
\begin{gathered}
R_{t}=\mu_{t}+a_{t}, a_{t}=\sigma_{t} e_{t}, \\
\sigma_{t}^{2}=\omega+\alpha_{1} a_{t-1}^{2}+\cdots+\alpha_{q} a_{t-q}^{2} .
\end{gathered}
$$

where $\left[e_{t}\right]$ is a sequence of independent and identically distributed (i.i.d.) random variables with mean zero, that is $\mathrm{E}\left(e_{t}\right)=0$ and variance 1 , that is $\mathrm{E}\left(e_{t}^{2}\right)=1, \omega>0$, and $\alpha_{1}, \cdots, \alpha_{q} \geq 0$ (Francq and Zakoian [2]). The coefficients $\alpha_{i}$, for $i>0$, must satisfy some regularity conditions to ensure that the unconditional variance of $a_{t}$ is finite.

\subsubsection{Generalized Autoregressive Conditional Heteroscedastic (GARCH) Model}

Although the ARCH model is simple, it often requires many parameters to adequately describe the volatility process of a share price return. Some alternative models must be sought. Bollerslev [12] proposed a useful extension known as the generalized ARCH (GARCH) model. For a return series, $R_{t}$, let $a_{t}=R_{t}-\mu_{t}$ be the innovation at time $t$. Then, $a_{t}$ follows a $\operatorname{GARCH}(q, p)$ model if

$$
\begin{gathered}
a_{t}=\sigma_{t} e_{t}, \\
\sigma_{t}^{2}=\omega+\sum_{i=1}^{q} \alpha_{i} a_{t-i}^{2}+\sum_{j=1}^{p} \beta_{j} \sigma_{t-j}^{2} .
\end{gathered}
$$

where again $e_{t}$ is a sequence of i.i.d. random variance with mean, 0 , and variance, $1, \omega>0, \alpha_{i} \geq 0, \beta_{j} \geq 0$ and $\sum_{i=1}^{\max (p, q)}\left(\alpha_{i}+\beta_{i}\right)<1 \quad$ (Tsay [13]). 
Here, it is understood that $\alpha_{i}=0$, for $i>p$, and $\beta_{i}=0$, for $i>q$. The latter constraint on $\alpha_{i}+\beta_{i}$ implies that the unconditional variance of $a_{t}$ is finite, whereas its conditional variance $\sigma_{t}^{2}$, evolves over time.

\subsubsection{Exponential Generalized Autoregressive Conditional Heteroscedastic (EGARCH) \\ Model}

The EGARCH model represents a major shift from ARCH and GARCH models (Nelson [14]). Rather than modeling the variance directly, EGARCH models the natural logarithm of the variance, and so no parameter restrictions are required to ensure that the conditional variance is positive. The $\operatorname{EGARCH}(q, p)$ is defined as,

$$
\begin{gathered}
R_{t}=\mu_{t}+a_{t}, a_{t}=\sigma_{t} e_{t}, \\
\ln \sigma_{t}^{2}=\omega+\sum_{i=1}^{q} \alpha_{i}\left|\frac{a_{t-i}}{\sqrt{\sigma_{t-i}^{2}}}\right|+\sum_{k=1}^{r} \gamma_{k}\left(\frac{a_{t-k}}{\sqrt{\sigma_{t-k}^{2}}}\right)+\sum_{j=1}^{p} \beta_{j} \ln \sigma_{t-j}^{2} .
\end{gathered}
$$

where again, $e_{t}$ is a sequence of i.i.d. random variance with mean, 0 , and variance, 1 , and $\gamma_{k}$ is the asymmetric coefficient.

\subsubsection{Glosten, Jagannathan and Runkle (GJR-GARCH) Model}

The GJR-GARCH $(q, p)$ model proposed by Glosten, Jagannathan and Runkle [15] is a variant, represented by

$$
\begin{gathered}
a_{t}=\sigma_{t} e_{t} \\
\sigma_{t}^{2}=\omega+\sum_{i=1}^{q} \alpha_{i} a_{t-i}^{2}+\sum_{i=1}^{p} \gamma_{i} I_{t-i} a_{t-i}^{2}+\sum_{j=1}^{p} \beta_{j} \sigma_{t-j}^{2} .
\end{gathered}
$$

where $I_{t-1}$ is an indicator for negative $a_{t-i}$, that is,

$$
I_{t-1}= \begin{cases}0 & \text { if } a_{t-i}<0 \\ 1 & \text { if } a_{t-i} \geq 0\end{cases}
$$

and $\alpha_{i}, \gamma_{i}$ and $\beta_{j}$ are nonnegative parameters satisfying conditions similar to those of GARCH models. Also the introduction of indicator parameter of leverage effect, $I_{t-1}$ in the model accommodates the leverage effect, since it is supposed that the effect of $a_{t-i}^{2}$ on the conditional variance $\sigma_{t}^{2}$ is different accordingly to the sign of $a_{t-i}$.

To successfully fit the processes describe by subsections 2.2 and 2.3, the approach is based on Box and Jenkins three iterative procedures which includes model identification, model estimation and diagnostic checking are summarized as follows.

Identification Stage: employs the plots of estimated acf (autocorrelation function) and pacf (partial autocorrelation function) as guides to selecting one or more ARIMA models that appears suitable. At this stage, models whose theoretical acf and pacf most closely resemble the estimated acf and pacf are selected tentatively.

Estimation Stage: The tentatively entertained model is fitted to data and its 
parameters estimated using maximum likelihood techniques.

Diagnostic checking Stage: Diagnostic checks are carried to help determine if an estimated model is statistically significant targeted at uncovering possible lack-of-fit. If no lack-of-fit is indicated, the model is ready to use. If any inadequacy is found, the iterative cycle of identification, estimation, and diagnostic checking is repeated until a suitable representation is found. (See Box, Jenkins and Reinsel [10]; Akpan, Lasisi and Adamu [8] for more details on the procedures and its application, respectively.)

\subsection{Outliers in Time Series}

Generally, a time series might contain several, say $k$ outliers of different types and we have the following general outlier model;

$$
Y_{t}=\sum_{j=1}^{k} \tau_{j} V_{j}(B) I_{t}^{(T)}+X_{t}
$$

where $X_{t}=(\theta(B)) /(\varphi(B)) a_{t}, V_{j}(B)=1$ for an $\mathrm{AO}$, and $V_{j}(B)=\frac{\theta(B)}{\varphi(B)}$ for an IO at $t=T_{j}, V_{j}(B)=(1-B)^{-1}$ for a LS, $V_{j}(B)=(1-\delta B)^{-1}$ for an TC, and $\tau$ is the size of outlier. For more details on the types of outliers and estimation of the outliers effects (see Moffat and Akpan [16]; Sanchez and Pena [17]; Box, Jenkins and Reinsel [10]; Wei [18]; Chen and Liu [19]; Chang, Tiao and Chen [20]).

Moreover, in financial time series, the residual series, $a_{t}$ is assumed to be uncorrelated with its own past, so additive, innovative, temporary change and level shift outliers coincide, and where both the mean and variance equations evolves together, we have for example GARCH( $(1,1)$ model:

$$
\begin{gathered}
R_{t}-\mu_{t}=\tilde{a}_{t}+\tau I_{t}^{(T)} . \\
\tilde{a}_{t}=\sigma_{t} e_{t} . \\
\sigma_{t}^{2}=\omega+\alpha_{1} \tilde{a}_{t-1}^{2}+\beta_{1} \sigma_{t-1}^{2} .
\end{gathered}
$$

where $\tilde{a}_{t}$ is the outliers contaminated residuals.

\subsection{Methods of Outliers Detection in Heteroscedasticity}

One approach for correcting the series for outliers is using standard criteria and then estimates the conditional variance. This approach involves detecting and correcting of outliers before estimating the conditional variance (Carnero, Pena and Ruiz [21]). This very method is based on the iterative framework of Chen and Liu [19] summarized in the following steps;

Step I: Given an ARIMA model fitted to the data, all the potential outliers are detected based on preliminary model parameter estimates.

Step II: Joint estimates of the model parameters and outliers effects are obtained using the accommodated outlier information of step I.

Step III: Outliers are identified and their effects estimated again based on the adjusted estimates of model parameters obtained in Step II. 


\subsection{Efficiency of Heteroscedastic Models}

Efficiency is a measure of quality of an estimator of a model. It is often expressed using variance or mean square error. For the purpose of this study which looks at a unified effect of outliers, unconditional variance and coefficient of kurtosis are considered as the measures of efficiency of estimator of heteroscedastic model. The application of coefficient of kurtosis in this case is to ensure that the existence of heavy-tailed is taken care of.

For $\operatorname{ARCH}(q)$ model which is equivalent to $\operatorname{GARCH}(q, 0)$ model, the unconditional variance is given as follows:

$$
\sigma^{2}=\frac{\omega}{1-\sum_{i=1}^{q} \alpha_{i}}
$$

For $\operatorname{GARCH}(q, p)$ model, the unconditional variance is expressed thus:

$$
\sigma^{2}=\frac{\omega}{1-\sum_{i=1}^{q} \alpha_{i}-\sum_{j=1}^{p} \beta_{i}} .
$$

For $\operatorname{EGARCH}(q, p)$ model, the unconditional variance is expressed as follows:

$$
\sigma^{2}=\exp \left(\frac{\omega}{1-\sum_{j=1}^{p} \beta_{i}}\right),
$$

where exp represent natural exponential function.

For GJR-GARCH $(q, p)$ model

$$
\sigma^{2}=\frac{\omega}{1-\sum_{i=1}^{q} \alpha_{i}-\sum_{i=1}^{q} \frac{\gamma_{i}}{2}-\sum_{j=1}^{p} \beta_{i}} .
$$

\subsection{Kurtosis}

Kurtosis coefficient for a centered (that is, zero-mean) distribution is defined as the ratio of the fourth-order moment, which is assumed to exist, to the squared second-order moment (Francq and Zakoian [2]). This coefficient is equal to 3 for a normal distribution (mesokurtosis). For heavy-tailed distribution, the coefficient is greater than 3 (leptokurtosis). The excess kurtosis of $\operatorname{GARCH}(1,1)$ model can be obtained as follows:

$$
\begin{gathered}
a_{t}=\sigma_{t} e_{t}, \\
\sigma_{t}^{2}=\omega+\alpha_{1} a_{t-1}^{2}+\beta_{1} \sigma_{t-1}^{2},
\end{gathered}
$$

Note that, $\mathrm{E}\left(e_{t}\right)=0, \operatorname{Var}\left(e_{t}\right)=1$, and $\mathrm{E}\left(e_{t}^{4}\right)=K_{e}+3$, where $K_{e}$ is the excess kurtosis of the innovation, $e_{t}$.

Also,

$$
\operatorname{Var}\left(a_{t}\right)=\mathrm{E}\left(\sigma_{t}^{2}\right)=\frac{\omega}{\left[1-\left(\alpha_{1}+\beta_{1}\right)\right]} .
$$

$\mathrm{E}\left(a_{t}^{4}\right)=\left(K_{e}+3\right) \mathrm{E}\left(\sigma_{t}^{4}\right)$ provided that $\mathrm{E}\left(\sigma_{t}^{4}\right)$ exists.

But, 


$$
\mathrm{E}\left(\sigma_{t}^{4}\right)=\frac{\omega^{2}\left(1+\alpha_{1}+\beta_{1}\right)}{\left[1-\left(\alpha_{1}+\beta_{1}\right)\right]\left[1-\alpha_{1}^{2}\left(K_{e}+2\right)-\left(\alpha_{1}+\beta_{1}\right)^{2}\right]},
$$

provided that $1>\alpha_{1}+\beta_{1} \geq 0$ and $1-\alpha_{1}^{2}\left(K_{e}+2\right)-\left(\alpha_{1}+\beta_{1}\right)^{2}>0$. the excess kurtosis of $a_{t}$, if it exists, is then

$$
K_{a}=\frac{\mathrm{E}\left(a_{t}^{4}\right)}{\left[\mathrm{E}\left(a_{t}^{2}\right)\right]^{2}}-3=\frac{\left(K_{e}+3\right)\left[1-\left(\alpha_{1}+\beta_{1}\right)^{2}\right]}{1-2 \alpha_{1}^{2}-\left(\alpha_{1}+\beta_{1}\right)^{2}-K_{e} \alpha_{1}^{2}}-3 .
$$

This excess kurtosis can be written in an informative expression. Considering the case where $e_{t}$ follows a normal distribution, $K_{e}=0$,

$$
K_{a}^{(g)}=\frac{6 \alpha_{1}^{2}}{1-2 \alpha_{1}^{2}-\left(\alpha_{1}+\beta_{1}\right)^{2}},
$$

where the superscript, $g$, is used to denote the Gaussian distribution. The same idea applies to other GARCH-type models (Tsay [13]).

\section{Results and Discussion}

\subsection{Data}

Data collection is based on secondary source as documented in the records of Nigerian Stock Exchange. The documented data on the daily closing share prices of the sampled banks (Skye bank, Sterling bank, Unity bank and Zenith bank) from January 3, 2006 to November 24, 2016 were purchased from the Nigerian Stock Exchange and delivered through contactcentre@nigerianstockexchange.com. Since the data were obtained from a credible and secured source therefore reliable.

\subsection{Interpretation of Time Plot}

The share prices of the four prominent Nigerian banks considered are found to be nonstationary given the random fluctuations away from the common mean (see Figures 1-4).

To achieve stationarity, Equation (1) was applied to the share price series and these transformed series were found to cluster round the common mean and thus indicated the presence of heteroscedasticity (see Figures 5-8).

\subsection{Modeling Joint ARIMA-GARCH-Type Processes of Return Series of Nigerian Banks}

Based on Box and Jenkins procedures, out of the several models identified tentatively, the following joint ARIMA-GARCH-type models with respect to both normal (norm) and student-t (std) distributions in (Table 1) were considered and selected on the grounds of smallest information criteria and model adequacy (see Table 2).

\subsection{Identification of Outliers in the Residual Series of ARIMA Models Fitted to the Return Series of Nigerian Bank}

Here, we examined the residuals series of the fitted ARIMA models for detection 


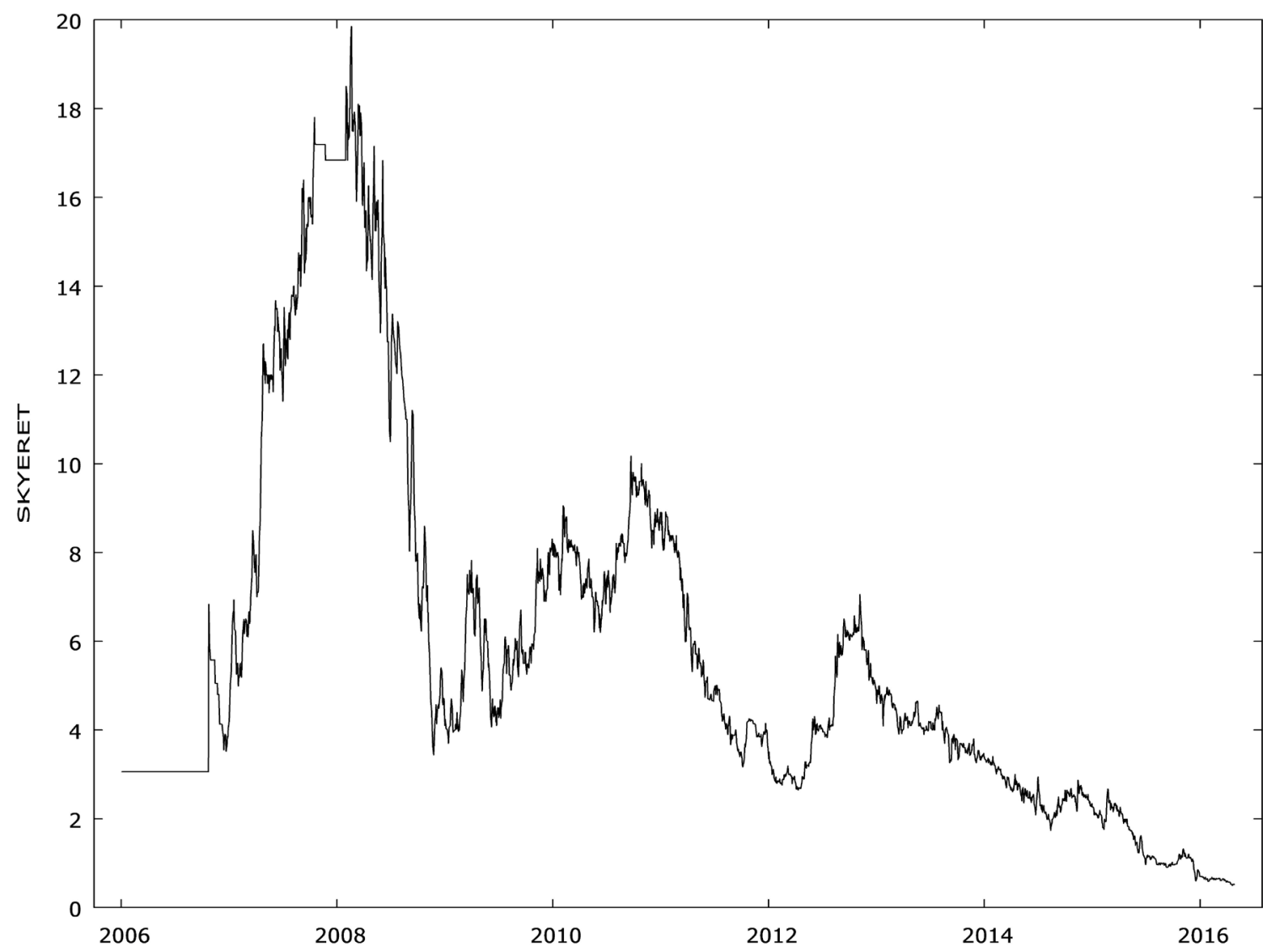

Figure 1. Share price series of Skye Bank.

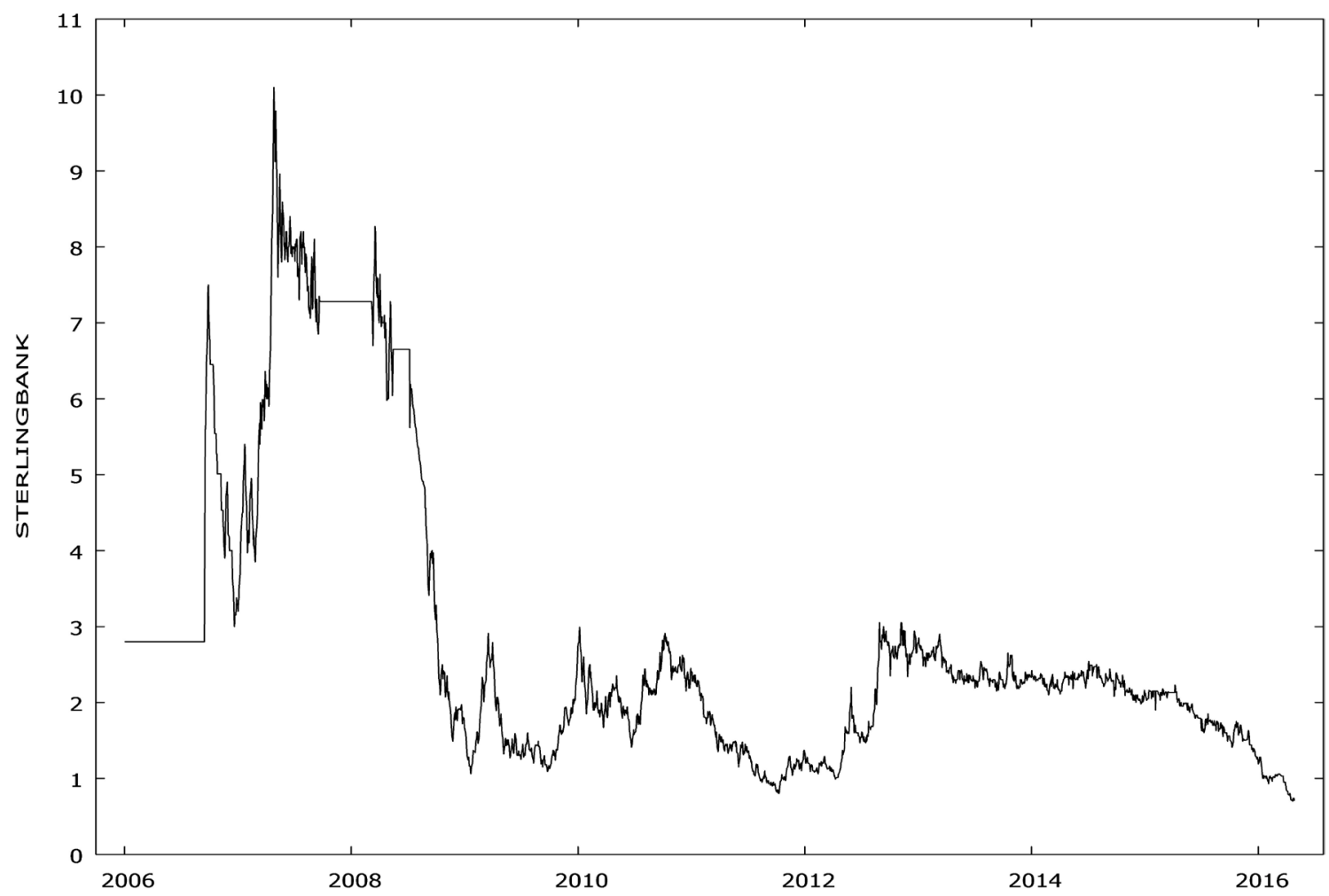

Figure 2. Share price series of Sterling Bank. 


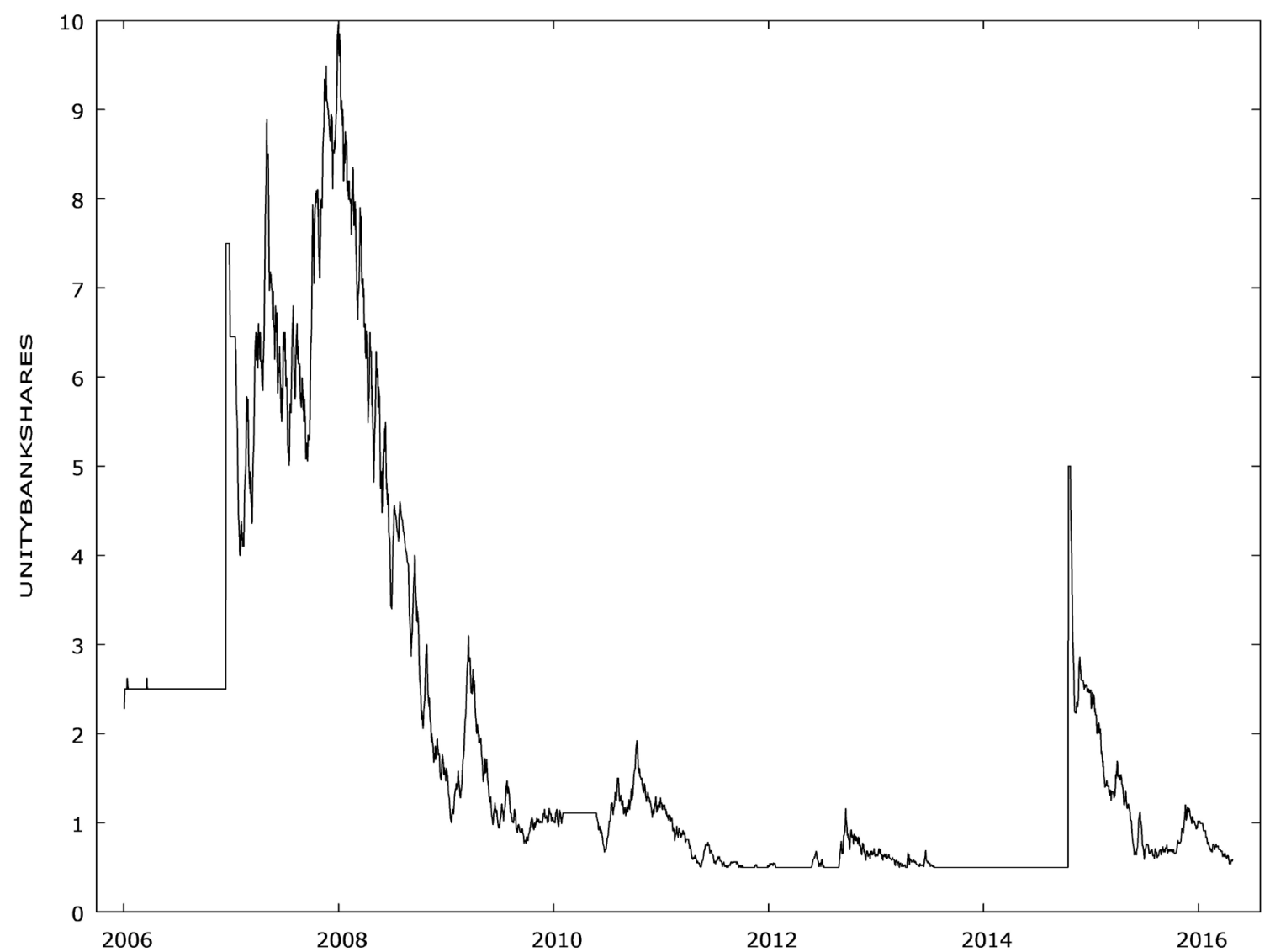

Figure 3. Share price series of Unity Bank.

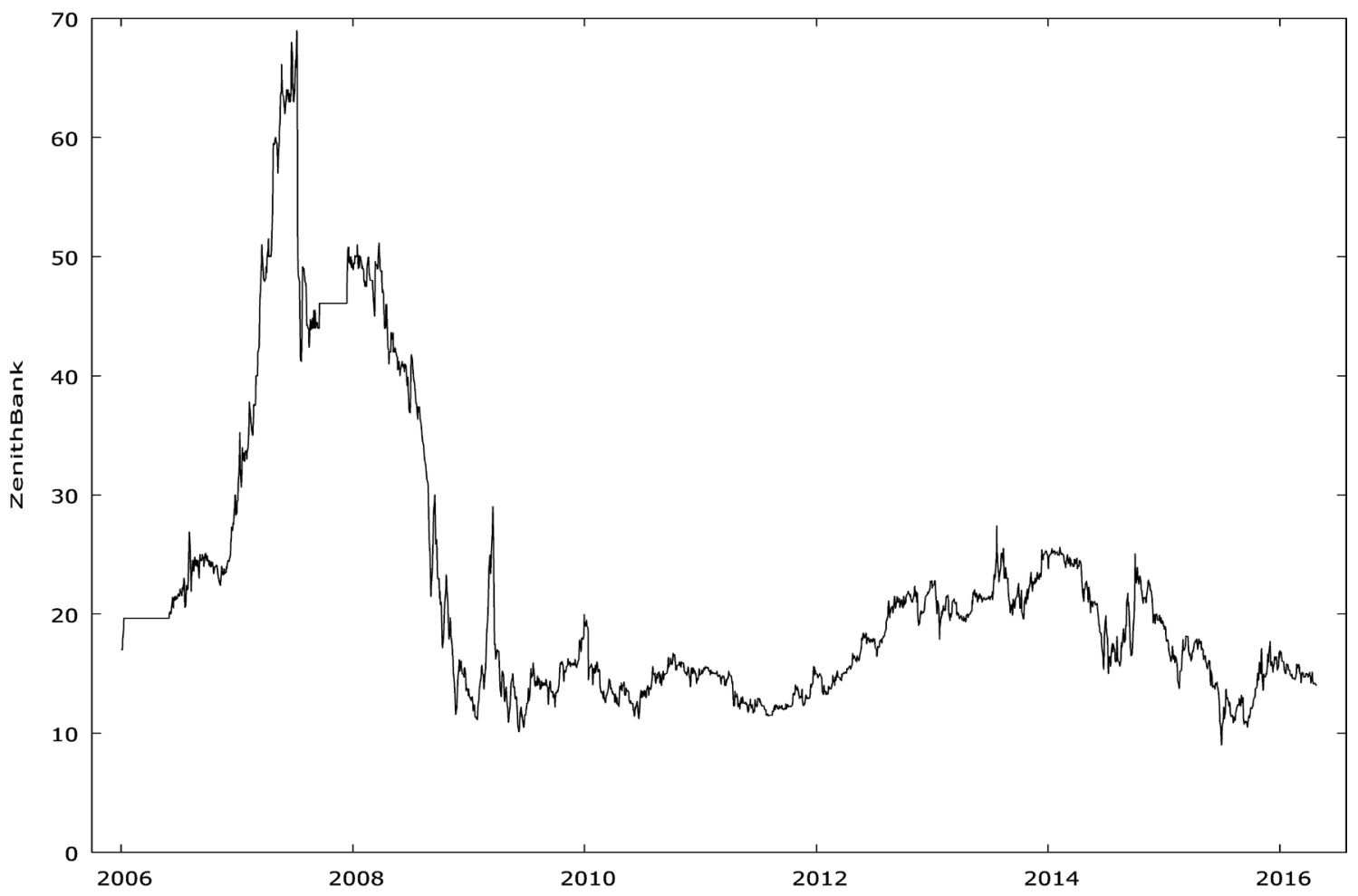

Figure 4. Share price series of Zenith Bank. 


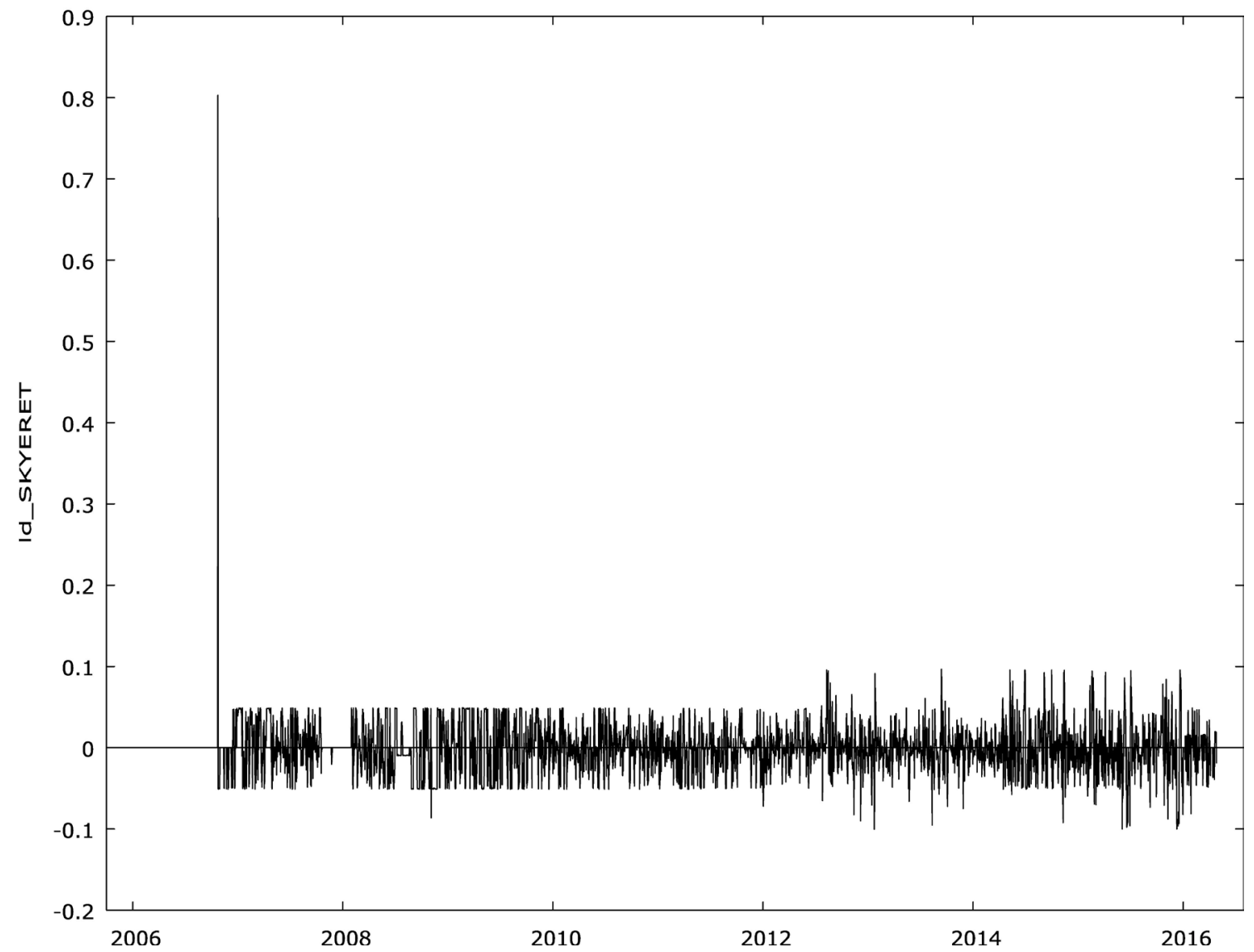

Figure 5. Return series of Skye Bank.

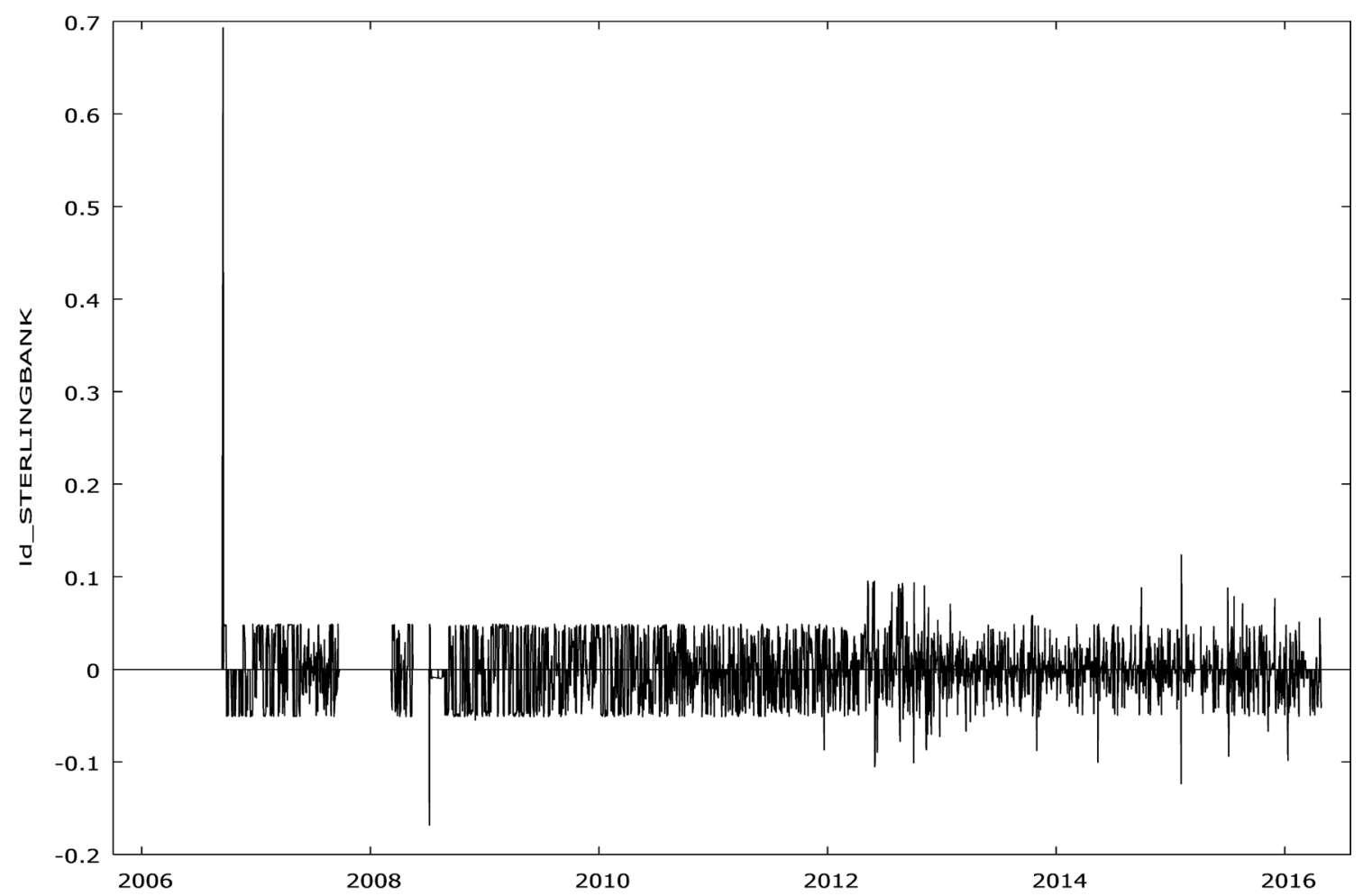

Figure 6. Return series of Sterling Bank. 


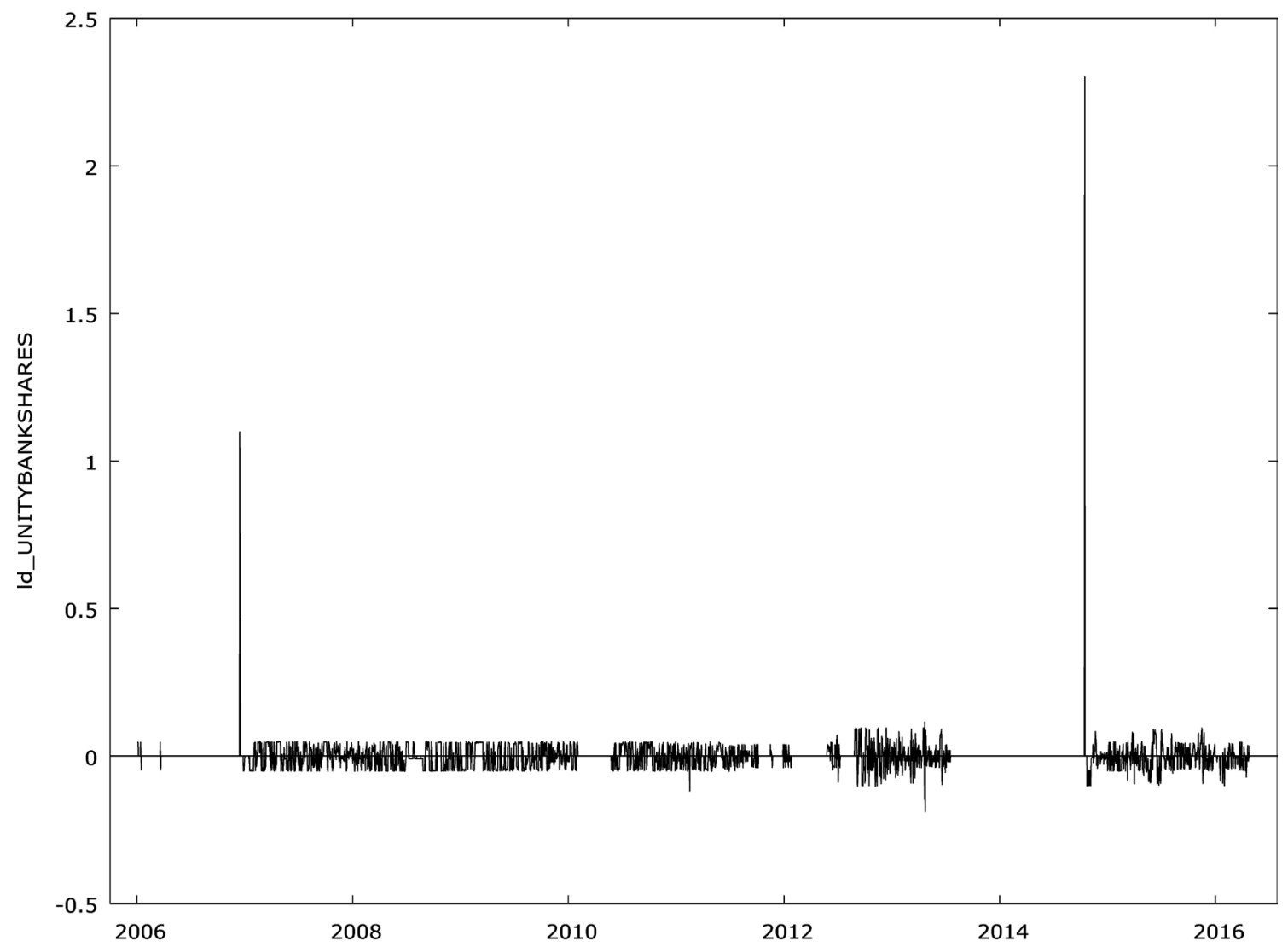

Figure 7. Return series of Unity Bank.

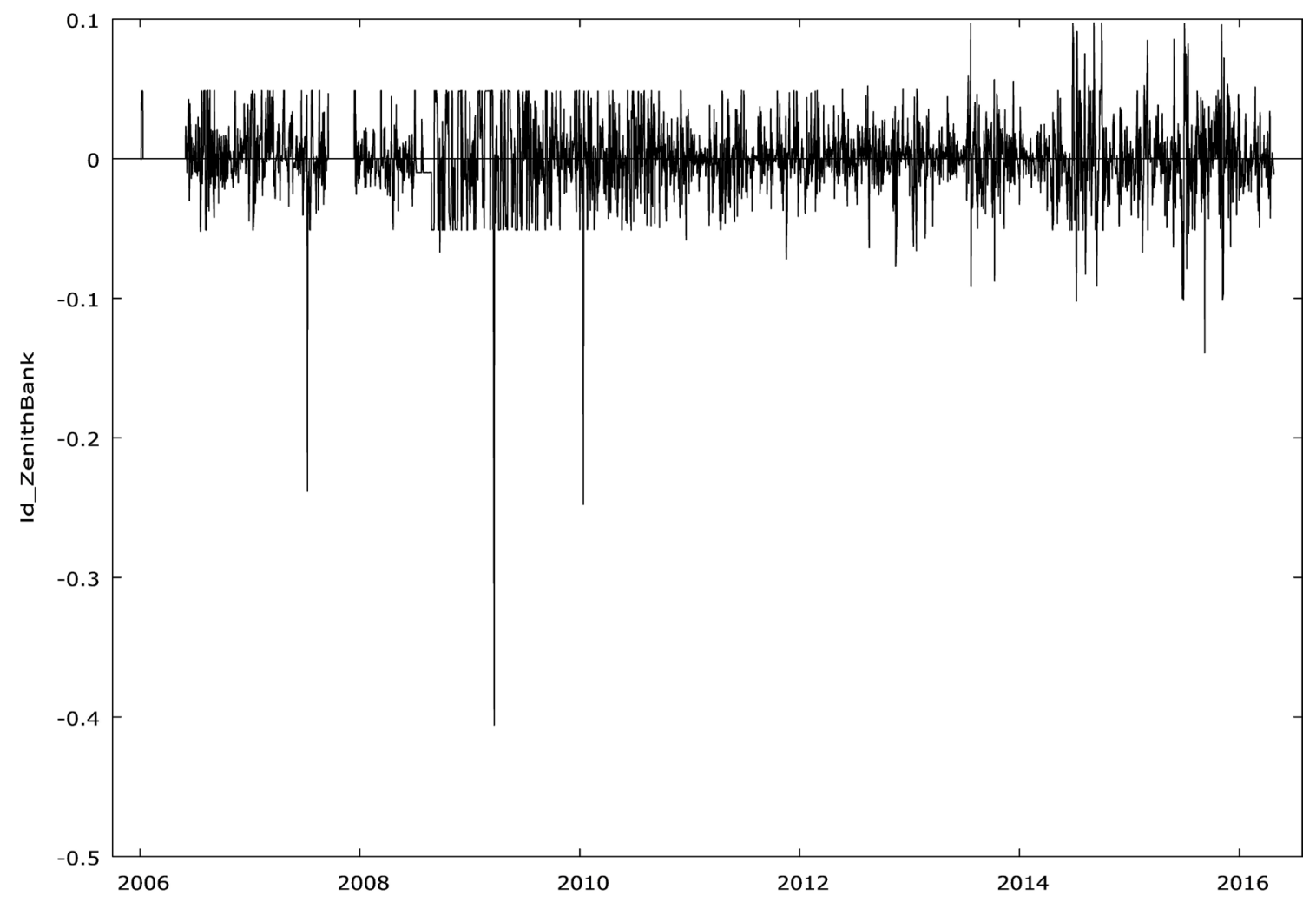

Figure 8. Return series of Zenith Bank. 
Table 1. Output of ARIMA-GARCH-type models of returns series of Nigerian Banks.

\begin{tabular}{|c|c|c|c|c|c|c|c|c|c|}
\hline \multirow{2}{*}{ Bank } & \multirow{2}{*}{ Model } & \multirow{2}{*}{ Parameter } & \multirow{2}{*}{ Estimate } & \multirow{2}{*}{ s.e } & \multirow{2}{*}{ t-ratio } & \multirow{2}{*}{ p-value } & \multicolumn{3}{|c|}{ Information Criteria } \\
\hline & & & & & & & AIC & BIC & HQIC \\
\hline \multirow[t]{5}{*}{ SKYE } & $\operatorname{ARIMA}(1,1,0)-\mathrm{GA}$ & $\mu$ & $-2.6 \mathrm{e}^{-5}$ & $1.1 \mathrm{e}^{-5}$ & -2.3973 & 0.0165 & & & \\
\hline & $\mathrm{RCH}(1,1)$-norm & $\varphi_{1}$ & $3.87 \mathrm{e}^{-4}$ & 0.0214 & 0.0181 & 0.9855 & & & \\
\hline & & $\omega$ & $2.0 \mathrm{e}^{-6}$ & 0.0000 & 73.3223 & 0.0000 & -4.5293 & -4.5183 & -4.5253 \\
\hline & & $\alpha_{1}$ & 0.1305 & $7.996 \mathrm{e}^{-3}$ & 16.3261 & 0.0000 & & & \\
\hline & & $\beta_{1}$ & 0.8685 & $6.671 \mathrm{e}^{-3}$ & 130.1908 & 0.0000 & & & \\
\hline \multirow[t]{7}{*}{ STERLING } & $\operatorname{ARIMA}(2,1,0)-\mathrm{EG}$ & $\mu$ & $-2.89 \mathrm{e}^{-4}$ & $1.57 \mathrm{e}^{-4}$ & -1.8335 & 0.06673 & & & \\
\hline & $\operatorname{ARCH}(1,1)$-norm & $\varphi_{1}$ & -0.0190 & 0.0102 & -1.8642 & 0.0623 & & & \\
\hline & & $\varphi_{2}$ & 0.0298 & $5.205 \mathrm{e}^{-3}$ & 5.7258 & 0.0000 & & & \\
\hline & & $\omega$ & -0.0943 & $1.607 \mathrm{e}^{-3}$ & -58.7069 & 0.0000 & -4.3888 & -4.3734 & -4.3832 \\
\hline & & $\alpha_{1}$ & -0.0734 & $4.024 \mathrm{e}^{-3}$ & -18.2286 & 0.0000 & & & \\
\hline & & $\beta_{1}$ & 0.9859 & $1.7 \mathrm{e}^{-5}$ & 5863.5496 & 0.0000 & & & \\
\hline & & $\gamma_{1}$ & 0.0975 & $3.588 \mathrm{e}^{-3}$ & 27.1638 & 0.0000 & & & \\
\hline \multirow[t]{5}{*}{ UNITY } & $\operatorname{ARIMA}(0,1,1)-$ & $\mu$ & $1.38 \mathrm{e}^{-4}$ & $1.9 \mathrm{e}^{-5}$ & 7.1606 & 0.0000 & & & \\
\hline & $\begin{array}{l}\text { GARCH } \\
(1,1) \text {-norm }\end{array}$ & $\theta_{1}$ & 0.1009 & 0.0236 & 4.2767 & $1.9 \mathrm{e}^{-5}$ & & & \\
\hline & & $\omega$ & $4.0 \mathrm{e}^{-6}$ & 0.0000 & 115.7800 & 0.0000 & -4.8711 & -4.8601 & -4.8671 \\
\hline & & $\alpha_{1}$ & 0.2368 & 0.0117 & 20.2352 & 0.0000 & & & \\
\hline & & $\beta_{1}$ & 0.7622 & $7.927 \mathrm{e}^{-3}$ & 96.1509 & 0.0000 & & & \\
\hline \multirow[t]{8}{*}{ ZENITH } & $\operatorname{ARIMA}(2,1,1)-\mathrm{EG}$ & $\mu$ & 0.0000 & 0.0000 & 1.2065 & 0.2276 & & & \\
\hline & ARCH $(1,1)$-std & $\varphi_{1}$ & -0.3086 & 0.0106 & -29.0801 & 0.0000 & & & \\
\hline & & $\varphi_{2}$ & 0.0495 & 0.0171 & 2.8972 & 0.0038 & & & \\
\hline & & $\theta_{1}$ & 0.2912 & 0.0105 & 27.7875 & 0.0000 & & & \\
\hline & & $\omega$ & -0.0291 & $8.62 \mathrm{e}^{-4}$ & -33.7888 & 0.0000 & -7.0189 & -6.9992 & -7.0118 \\
\hline & & $\alpha_{1}$ & -0.6979 & $9.8 e^{-5}$ & -7150.4179 & 0.0000 & & & \\
\hline & & $\beta_{1}$ & 0.9996 & $6.3 e^{-5}$ & 15825.7924 & 0.0000 & & & \\
\hline & & $\gamma_{1}$ & 0.6983 & $9.8 \mathrm{e}^{-5}$ & 7147.6333 & 0.0000 & & & \\
\hline
\end{tabular}

of possible potential outliers in the returns series of the banks under study. The iterative procedure of Chen and Liu [19] was applied and those statistics that are in absolute value higher than a threshold (critical value, $\mathrm{C}$ ) identify the time point of a potential outlier. In this study, $\mathrm{C}=4$ is chosen on the condition that the number of observations, $T \geq 450$ and where $C=4$ is not sufficient, $C=5$ is used. 
Table 2. Diagnostic Checking for ARIMA-GARCH-type models of returns series of Nigerian Banks

\begin{tabular}{|c|c|c|c|c|c|c|c|c|c|c|}
\hline \multirow[b]{2}{*}{ Bank } & \multirow[b]{2}{*}{ Model } & \multicolumn{3}{|c|}{ Standardized Residuals } & \multicolumn{6}{|c|}{ Standardized Squared Residuals } \\
\hline & & Lag & $\begin{array}{c}\text { Weighted } \\
\text { LB }\end{array}$ & $\mathrm{p}$-value & Lag & $\begin{array}{c}\text { Weighted } \\
\text { LB }\end{array}$ & $\mathrm{p}$-value & Lag & $\begin{array}{l}\text { Weighted } \\
\text { ARCH -LM }\end{array}$ & p-value \\
\hline \multirow[t]{3}{*}{ SKYE } & $\operatorname{ARIMA}(1,1,0)-\mathrm{GA}$ & 1 & 0.0132 & 0.9085 & 1 & 0.0004 & 0.9833 & 3 & 0.0005 & 0.9829 \\
\hline & $\mathrm{RCH}(1,1)$-norm & 2 & 0.015 & 1.0000 & 5 & 0.0014 & 1.000 & 5 & 0.0011 & 1.0000 \\
\hline & & 5 & 0.0237 & 1.0000 & 9 & 0.0023 & 1.000 & 7 & 0.0016 & 1.0000 \\
\hline \multirow[t]{3}{*}{ STERLING } & $\operatorname{ARIMA}(2,1,0)-\mathrm{EG}$ & 1 & 0.0944 & 0.7587 & 1 & 0.0003 & 0.9851 & 3 & 0.0004 & 0.9837 \\
\hline & $\operatorname{ARCH}(1,1)$-norm & 5 & 0.1192 & 1.0000 & 5 & 0.0012 & 1.0000 & 5 & 0.0010 & 1.0000 \\
\hline & & 9 & 0.1588 & 1.0000 & 9 & 0.0021 & 1.0000 & 7 & 0.0015 & 1.0000 \\
\hline \multirow[t]{3}{*}{ UNITY } & $\operatorname{ARIMA}(0,1,1)-$ & 1 & 0.0031 & 0.9557 & 1 & 0.0008 & 0.9776 & 3 & 0.0008 & 0.9776 \\
\hline & $\begin{array}{c}\text { GARCH } \\
(1,1) \text {-norm }\end{array}$ & 2 & 0.0031 & 1.0000 & 5 & 0.0024 & 1.0000 & 5 & 0.0019 & 1.0000 \\
\hline & & 5 & 0.0035 & 1.0000 & 9 & 0.0039 & 1.0000 & 7 & 0.0028 & 1.0000 \\
\hline \multirow[t]{3}{*}{ ZENITH } & $\operatorname{ARIMA}(2,1,1)-\mathrm{EG}$ & 1 & 0.0014 & 0.9697 & 1 & 0.0014 & 0.9704 & 3 & 0.0014 & 0.9704 \\
\hline & $\operatorname{ARCH}(1,1)-$ std & 8 & 0.0066 & 1.0000 & 5 & 0.0041 & 1.0000 & 5 & 0.0033 & 0.9999 \\
\hline & & 14 & 0.0111 & 1.0000 & 9 & 0.0069 & 1.0000 & 7 & 0.0049 & 1.0000 \\
\hline
\end{tabular}

LB = Ljung-Box, $\mathrm{LM}=$ Lagrange Multiplier.

\subsubsection{Identification of Outliers in the Residual Series of ARIMA $(1,1,0)$} Model Fitted to the Return Series of Skye Bank

About twenty six (26) different outliers were identified to have contaminated the residuals series of $\operatorname{ARIMA}(1,1,0)$ model using the critical value, $C=4$; six (6) innovation outliers (IO), six (6) additive outliers (AO) and fourteen (14) temporary change (TC) as indicated in (Table 3 ).

\subsubsection{Identification of Outliers in the Residual Series of ARIMA $(2,1,0)$ Model Fitted to the Return Series of Sterling Bank}

About seven (7) different outliers were identified to have contaminated the residual series of $\operatorname{ARIMA}(2,1,0)$ model using the critical value, $C=5$ one (1) innovation outlier (IO), four (4) additive outliers (AO) and two (2) temporary change (TC) as shown in (Table 4).

\subsubsection{Identification of Outliers in the Residual Series of ARIMA $(1,1,0)$ Model Fitted to the Return Series of Unity Bank}

About thirty three (33) different outliers were identified to have contaminated the residual series of $\operatorname{ARIMA}(1,1,0)$ model using the critical value, $C=5$; two (2) innovation outliers (IO), six (6) additive outliers, fifteen (15) temporary change (TC) and ten (10) level shift (LS) as indicated in (Table 5).

\subsubsection{Identification of Outliers in the Residual Series of ARIMA $(2,1,1)$ Model Fitted to the Return Series of Zenith Bank}

About forty two (42) different outliers were identified to have contaminated the residual series of $\operatorname{ARIMA}(2,1,1)$ model using the critical value, $C=5$; thirteen (13) innovation outliers (IO), nine (9) additive outliers and twenty (20) temporary change (TC) as shown in (Table 6). 
Table 3. Outliers identified in the residual series of $\operatorname{ARIMA}(1,1,0)$ model fitted to return series of Skye Bank.

\begin{tabular}{|c|c|c|c|c|}
\hline Type & Observation index & Location & Estimate & T-statistic \\
\hline IO & 211 & $13 / 11 / 2006$ & -0.20150630 & -8.487698 \\
\hline IO & 1841 & $21 / 06 / 2013$ & -0.10241849 & -4.313995 \\
\hline IO & 1843 & $25 / 06 / 2013$ & 0.09870872 & 4.157735 \\
\hline IO & 2178 & $31 / 10 / 2014$ & 0.10295915 & 4.336768 \\
\hline IO & 2263 & $05 / 05 / 2015$ & 0.09758512 & 4.110407 \\
\hline IO & 210 & $10 / 11 / 2006$ & 0.81215294 & 34.804236 \\
\hline $\mathrm{AO}$ & 1726 & $04 / 01 / 2013$ & 0.09492679 & 4.068020 \\
\hline $\mathrm{AO}$ & 1984 & $21 / 01 / 2014$ & -0.10371058 & -4.444443 \\
\hline $\mathrm{AO}$ & 2281 & $31 / 05 / 2015$ & 0.09978000 & 4.276001 \\
\hline $\mathrm{AO}$ & 2414 & $15 / 10 / 2015$ & 0.10169110 & 4.357900 \\
\hline $\mathrm{AO}$ & 2456 & $14 / 12 / 2015$ & -0.09871728 & -4.230459 \\
\hline $\mathrm{AO}$ & 209 & $09 / 11 / 2006$ & 0.20948475 & 10.861708 \\
\hline $\mathrm{TC}$ & 740 & 09/01/2009 & -0.09161349 & -4.750126 \\
\hline $\mathrm{TC}$ & 742 & $12 / 01 / 2009$ & -0.07866550 & -4.078778 \\
\hline $\mathrm{TC}$ & 827 & $18 / 05 / 2009$ & 0.07862559 & 4.076708 \\
\hline $\mathrm{TC}$ & 1723 & $13 / 12 / 2012$ & 0.08946532 & 4.638744 \\
\hline $\mathrm{TC}$ & 2311 & $15 / 05 / 2015$ & 0.09068887 & 4.702185 \\
\hline $\mathrm{TC}$ & 2381 & $26 / 08 / 2015$ & 0.09747559 & 5.054074 \\
\hline $\mathrm{TC}$ & 2468 & $05 / 01 / 2016$ & -0.10240036 & -5.309421 \\
\hline $\mathrm{TC}$ & 2590 & $29 / 06 / 2016$ & -0.08395679 & -4.353129 \\
\hline $\mathrm{TC}$ & 2592 & $01 / 07 / 2016$ & -0.12692535 & -6.581033 \\
\hline $\mathrm{TC}$ & 2599 & $15 / 07 / 2016$ & 0.10544854 & 5.467469 \\
\hline $\mathrm{TC}$ & 2314 & $20 / 05 / 2015$ & -0.10163346 & -4.363007 \\
\hline $\mathrm{TC}$ & 212 & $14 / 11 / 2006$ & -0.10846069 & -5.731470 \\
\hline $\mathrm{TC}$ & 741 & $12 / 01 / 2009$ & 0.07648229 & 4.225631 \\
\hline $\mathrm{TC}$ & 2589 & $28 / 06 / 2016$ & 0.07256176 & 4.009023 \\
\hline
\end{tabular}

Table 4. Outliers identified in the residual series of $\operatorname{ARIMA}(2,1,0)$ model fitted to return series of Sterling Bank.

\begin{tabular}{ccccc}
\hline Type & Observation index & Location & Estimate & T-statistic \\
\hline AO & 184 & $03 / 10 / 2006$ & 0.6913146 & 27.668748 \\
AO & 655 & $02 / 09 / 2008$ & -0.1764822 & -7.063413 \\
AO & 2371 & $12 / 08 / 2015$ & -0.1398721 & -5.598155 \\
TC & 183 & $29 / 09 / 2006$ & 0.2415834 & 11.950355 \\
TC & 1672 & $22 / 05 / 2012$ & -0.1075351 & -5.319415 \\
IO & 185 & $04 / 10 / 2006$ & -0.1964258 & -7.900298 \\
AO & 2372 & $12 / 08 / 2015$ & 0.1407112 & 5.678009 \\
\hline
\end{tabular}


Table 5. Outliers identified in the residual series of $\operatorname{ARIMA}(1,1,0)$ model fitted to return series of Unity Bank.

\begin{tabular}{|c|c|c|c|c|}
\hline Type & Observation index & Location & Estimate & T-statistic \\
\hline IO & 2293 & $20 / 04 / 2015$ & -0.180979695 & -7.444781 \\
\hline $\mathrm{AO}$ & 248 & $10 / 01 / 2007$ & 1.098612289 & 45.331893 \\
\hline $\mathrm{AO}$ & 1906 & $24 / 09 / 2013$ & -0.200532990 & -8.274566 \\
\hline $\mathrm{AO}$ & 2292 & $17 / 04 / 2015$ & 2.302585093 & 95.011264 \\
\hline $\mathrm{TC}$ & 247 & $09 / 01 / 2007$ & 0.365004553 & 19.903211 \\
\hline $\mathrm{TC}$ & 1736 & $18 / 01 / 2013$ & 0.107790532 & 5.877674 \\
\hline $\mathrm{TC}$ & 1745 & $01 / 02 / 2013$ & 0.112419182 & 6.130068 \\
\hline $\mathrm{TC}$ & 1753 & $13 / 02 / 2013$ & -0.118923561 & -6.484743 \\
\hline TC & 1762 & $26 / 02 / 2013$ & 0.091895380 & 5.010932 \\
\hline $\mathrm{TC}$ & 2291 & $16 / 04 / 2015$ & 0.758297010 & 41.348923 \\
\hline $\mathrm{TC}$ & 2298 & $27 / 04 / 2015$ & -0.142415961 & -7.765752 \\
\hline $\mathrm{TC}$ & 2304 & $06 / 04 / 2015$ & -0.098876918 & -5.391626 \\
\hline TC & 2446 & $30 / 11 / 2015$ & -0.093629262 & -5.105479 \\
\hline TC & 2458 & $16 / 12 / 2015$ & 0.112419118 & 6.130064 \\
\hline $\mathrm{TC}$ & 2460 & $18 / 12 / 2015$ & 0.104980801 & 5.724463 \\
\hline TC & 2467 & $04 / 01 / 2016$ & -0.106045605 & -5.782525 \\
\hline $\mathrm{TC}$ & 2469 & $06 / 01 / 2016$ & -0.119002493 & -6.489047 \\
\hline IO & 1905 & $23 / 09 / 2013$ & 0.127354627 & 5.132279 \\
\hline $\mathrm{AO}$ & 1904 & $20 / 09 / 2013$ & -0.163097022 & -6.592937 \\
\hline LS & 243 & $29 / 12 / 2006$ & -0.003141767 & -5.772181 \\
\hline LS & 251 & $15 / 01 / 2007$ & -0.002771753 & -5.084049 \\
\hline LS & 347 & $11 / 06 / 2007$ & -0.002837928 & -5.102009 \\
\hline LS & 520 & $19 / 06 / 2008$ & -0.003114010 & -5.387808 \\
\hline LS & 598 & $13 / 06 / 2008$ & -0.003027395 & -5.143002 \\
\hline LS & 613 & $04 / 07 / 2008$ & -0.003035068 & -5.137530 \\
\hline LS & 631 & $30 / 07 / 2008$ & -0.002988789 & -5.037234 \\
\hline LS & 635 & $05 / 08 / 2008$ & -0.003001055 & -5.052994 \\
\hline LS & 2286 & $09 / 04 / 2015$ & -0.008202488 & -6.130741 \\
\hline $\mathrm{TC}$ & 1901 & $17 / 09 / 2013$ & 0.097493034 & 5.208012 \\
\hline TC & 2477 & $18 / 01 / 2016$ & 0.096324642 & 5.145597 \\
\hline LS & 607 & $26 / 06 / 2008$ & 0.022239276 & 28.623733 \\
\hline $\mathrm{AO}$ & 1336 & 09/06/2011 & -0.128187865 & -5.110079 \\
\hline $\mathrm{AO}$ & 1872 & $05 / 08 / 2013$ & -0.144642972 & -5.766045 \\
\hline
\end{tabular}


Table 6. Outliers identified in the residual series of $\operatorname{ARIMA}(2,1,1)$ model fitted to return series of Zenith Bank.

\begin{tabular}{|c|c|c|c|c|}
\hline Type & Observation index & Location & Estimate & T-statistic \\
\hline IO & 396 & $17 / 08 / 2007$ & -0.09816377 & -13.221339 \\
\hline IO & 840 & $05 / 06 / 2009$ & 0.04253167 & 5.728444 \\
\hline IO & 2221 & $06 / 01 / 2015$ & -0.03927918 & -5.29037 \\
\hline IO & 2263 & $05 / 03 / 2015$ & 0.04378397 & 5.897112 \\
\hline IO & 2281 & $18 / 03 / 2013$ & 0.03787680 & 5.101495 \\
\hline IO & 2473 & $12 / 01 / 2016$ & -0.03936074 & -5.301362 \\
\hline IO & 2475 & $14 / 01 / 2016$ & -0.04230834 & -5.698364 \\
\hline IO & 2525 & $24 / 03 / 2016$ & -0.06416968 & -8.642792 \\
\hline IO & 2565 & $24 / 05 / 2016$ & 0.04357221 & 5.868590 \\
\hline IO & 2568 & $27 / 05 / 2016$ & -0.03892676 & -5.242911 \\
\hline $\mathrm{AO}$ & 839 & $04 / 06 / 2009$ & -0.17023181 & -23.610345 \\
\hline $\mathrm{AO}$ & 1051 & $13 / 04 / 2010$ & -0.10685231 & -14.819909 \\
\hline $\mathrm{AO}$ & 1971 & $31 / 12 / 2013$ & -0.04930715 & -6.838668 \\
\hline $\mathrm{AO}$ & 2027 & $21 / 03 / 2014$ & -0.04348949 & -6.031786 \\
\hline $\mathrm{AO}$ & 2223 & $08 / 01 / 2015$ & 0.04365213 & 6.054343 \\
\hline $\mathrm{AO}$ & 2389 & $07 / 09 / 2015$ & 0.03931499 & 5.452803 \\
\hline $\mathrm{AO}$ & 2453 & $09 / 12 / 2015$ & 0.04052320 & 5.620376 \\
\hline $\mathrm{AO}$ & 2483 & $26 / 01 / 2016$ & -0.03680867 & -5.105188 \\
\hline $\mathrm{TC}$ & 395 & $16 / 08 / 2007$ & -0.04944665 & -8.279793 \\
\hline $\mathrm{TC}$ & 691 & $27 / 10 / 2008$ & -0.03018987 & -5.055264 \\
\hline $\mathrm{TC}$ & 710 & $21 / 11 / 2008$ & -0.03064893 & -5.132133 \\
\hline $\mathrm{TC}$ & 747 & $20 / 01 / 2009$ & -0.03068035 & -5.137395 \\
\hline $\mathrm{TC}$ & 802 & $08 / 04 / 2009$ & 0.02900192 & 5.029855 \\
\hline TC & 838 & $03 / 06 / 2009$ & -0.05601975 & -9.380451 \\
\hline $\mathrm{TC}$ & 2477 & $18 / 01 / 2016$ & 0.03332783 & 5.580712 \\
\hline IO & 1970 & $30 / 12 / 2013$ & 0.03696756 & 5.089711 \\
\hline IO & 2269 & $13 / 03 / 2015$ & -0.03667538 & -5.049484 \\
\hline $\mathrm{TC}$ & 698 & $05 / 11 / 2008$ & 0.03138467 & 5.372151 \\
\hline $\mathrm{TC}$ & 754 & $29 / 01 / 2009$ & 0.03144461 & 5.382412 \\
\hline $\mathrm{TC}$ & 802 & $08 / 04 / 2009$ & 0.02900192 & 5.029855 \\
\hline IO & 2569 & $31 / 05 / 2016$ & -0.04117313 & -5.684147 \\
\hline $\mathrm{TC}$ & 394 & $15 / 08 / 2007$ & 0.03079012 & 5.941387 \\
\hline TC & 833 & $26 / 05 / 2009$ & 0.02933330 & 5.660273 \\
\hline $\mathrm{TC}$ & 850 & $19 / 06 / 2009$ & -0.02610763 & -5.037836 \\
\hline $\mathrm{TC}$ & 2212 & $18 / 12 / 2014$ & 0.02755604 & 5.317326 \\
\hline
\end{tabular}


Continued

\begin{tabular}{lcccc}
\hline AO & 2282 & $25 / 01 / 2016$ & 0.03601640 & 5.029504 \\
TC & 2484 & $27 / 01 / 2016$ & 0.02586343 & 5.048003 \\
TC & 824 & $13 / 05 / 2009$ & 0.02437288 & 5.000302 \\
TC & 890 & $14 / 08 / 2009$ & -0.02533852 & -5.198411 \\
TC & 2217 & $29 / 12 / 2014$ & -0.02467081 & -5.061424 \\
TC & 2450 & $04 / 12 / 2015$ & -0.02471591 & -5.070677 \\
TC & 919 & $28 / 09 / 2009$ & 0.02369936 & 5.067229 \\
\hline
\end{tabular}

\subsection{Modeling Joint ARIMA-GARCH-Type Processes of Outlier Adjusted Return Series of Nigerian Banks}

However, with the identified outliers being adjusted for, we obtained a new series (outlier adjusted return series). Again, Box and Jenkins iterative procedures were applied and those models in (Table 7) were selected based on smallest information criteria and model adequacy (Table 8).

\subsection{Determination of Efficiency of ARIMA-GARCH-Type Models of Returns Series of Nigerian Banks}

The ARIMA(1, 1, 0)-GARCH(1, 1)-norm model fitted to both outlier adjusted return series and outlier contaminated series with the same unconditional variance, 0.0016. Again, the value of kurtosis, 2.9465 captured by $\operatorname{GARCH}(1$, 1)-norm model on outlier adjusted return series is nearly the value accommodated by the normal distribution while $\operatorname{GARCH}(1,1)$-norm model on outlier contaminated series seems inferior with excess kurtosis of 132.8707 (see Table 9).

From (Table 10), evidence shows that $\operatorname{ARIMA}(2,1,2)-\operatorname{EGARCH}(1,1)$-std model fitted to outlier adjusted return series appeared to be more efficient given that the unconditional variance and kurtosis coefficient are smaller than that of the $\operatorname{ARIMA}(2,1,0)$-EGARCH$(1,1)$-norm model fitted to the outlier contaminated series.

From (Table 11), evidence shows that $\operatorname{ARIMA}(1,1,0)-G)$ R-GARCH(1, 0 )-norm model fitted to outlier adjusted return series appeared to be more efficient given that the unconditional variance and kurtosis value are smaller than that of the ARIMA $(0,1,1)$-GARCH$(1,1)$-norm model fitted to the outlier contaminated series.

The $\operatorname{ARIMA}(2,1,1)$-EGARCH$(1,1)$-std model fitted to both outlier adjusted return series and outlier contaminated series converges to respective unconditional variances of $5.118125 \mathrm{e}^{-5}$ and $5.887684 \mathrm{e}^{-36}$ with corresponding kurtosis values of 3.5746 and 26.3794. Though, the unconditional variance of ARIMA(2, $1,1)$-EGARCH$(1,1)$-std model fitted to the outlier contaminated series is smaller than that of the outlier adjusted return series, the model for the outlier adjusted return series is more efficient given that the kurtosis value is near three, the value occupied by normal distribution (Table 12). 
Table 7. Output of ARIMA-GARCH-type models of outlier adjusted returns series of Nigerian Banks.

\begin{tabular}{|c|c|c|c|c|c|c|c|c|c|}
\hline \multirow{2}{*}{ Bank } & \multirow{2}{*}{ Model } & \multirow{2}{*}{ Parameter } & \multirow{2}{*}{ Estimate } & \multirow{2}{*}{ s.e } & \multirow{2}{*}{ t-ratio } & \multirow{2}{*}{$\mathrm{p}$-value } & \multicolumn{3}{|c|}{ Information Criteria } \\
\hline & & & & & & & AIC & BIC & HQIC \\
\hline \multirow{5}{*}{ SKYE } & \multirow{5}{*}{$\begin{array}{c}\operatorname{ARIMA}(1,1,0) \\
\text {-GARCH }(1,1)- \\
\text { norm }\end{array}$} & $\mu$ & $-1.36 \mathrm{e}^{-4}$ & $5.0 \mathrm{e}^{-6}$ & -25.9283 & 0.0000 & \multirow{5}{*}{-4.6518} & \multirow{5}{*}{-4.6409} & \multirow{5}{*}{-4.6479} \\
\hline & & $\varphi_{1}$ & -0.0466 & 0.0211 & -2.2101 & 0.0271 & & & \\
\hline & & $\omega$ & $2.0 \mathrm{e}^{-6}$ & 0.0000 & 67.0558 & 0.0000 & & & \\
\hline & & $\alpha_{1}$ & 0.1228 & $7.675 \mathrm{e}^{-3}$ & 15.9933 & 0.0000 & & & \\
\hline & & $\beta_{1}$ & 0.8762 & $6.665 \mathrm{e}^{-3}$ & 131.4656 & 0.0000 & & & \\
\hline \multirow{10}{*}{ STERLING } & \multirow{10}{*}{$\begin{array}{c}\text { ARIMA } \\
(2,1,2)-\text { EGAR } \\
\text { CH( }(1,1) \text {-std }\end{array}$} & $\mu$ & 0.0000 & 0.0000 & -1.51 & 0.1310 & \multirow{10}{*}{-5.7621} & \multirow{10}{*}{-5.7401} & \multirow{10}{*}{-5.7541} \\
\hline & & $\varphi_{1}$ & $6.085 \mathrm{e}^{-3}$ & $1.0 \mathrm{e}^{-6}$ & 5673.10 & 0.0000 & & & \\
\hline & & $\varphi_{2}$ & 0.9386 & $1.58 \mathrm{e}^{-4}$ & 5935.97 & 0.0000 & & & \\
\hline & & $\theta_{1}$ & 0.2025 & $3.2 \mathrm{e}^{-5}$ & 6283.61 & 0.0000 & & & \\
\hline & & $\theta_{2}$ & -0.7371 & $1.2 \mathrm{e}^{-4}$ & -6163.17 & 0.0000 & & & \\
\hline & & $\omega$ & -0.0929 & $2.74 \mathrm{e}^{-4}$ & -338.38 & 0.0000 & & & \\
\hline & & $\alpha_{1}$ & 0.5597 & $6.7 \mathrm{e}^{-5}$ & 8413.54 & 0.0000 & & & \\
\hline & & $\beta_{1}$ & 0.9925 & $1.42 \mathrm{e}^{-4}$ & 6970.63 & 0.0000 & & & \\
\hline & & $\gamma_{1}$ & 0.5599 & $6.5 \mathrm{e}^{-5}$ & 8667.79 & 0.0000 & & & \\
\hline & & $\mu$ & $-2.284 \mathrm{e}^{-3}$ & $1.0 \mathrm{e}^{-5}$ & -220.0970 & 0.0000 & & & \\
\hline \multirow{4}{*}{ UNITY } & \multirow{4}{*}{$\begin{array}{c}\text { ARIMA }(1,1,0) \\
\text {-GJR-GARCH } \\
(1,0) \text {-norm }\end{array}$} & $\varphi_{1}$ & 0.0559 & $2.66 \mathrm{e}^{-4}$ & 209.9780 & 0.0000 & \multirow{4}{*}{-4.2296} & \multirow{4}{*}{-4.2406} & \multirow{4}{*}{-4.2336} \\
\hline & & $\omega$ & $1.0 \mathrm{e}^{-6}$ & 0.0000 & 3.4940 & 0.0005 & & & \\
\hline & & $\alpha_{1}$ & 0.8566 & $3.888 \mathrm{e}^{-3}$ & 220.3020 & 0.0000 & & & \\
\hline & & $\gamma_{1}$ & 0.2175 & 0.0114 & 19.0470 & 0.0000 & & & \\
\hline \multirow{8}{*}{ ZENITH } & \multirow{8}{*}{$\begin{array}{c}\operatorname{ARIMA}(2,1,1) \\
\text {-EGARCH}(1,1 \\
) \text {-std }\end{array}$} & $\mu$ & 0.0000 & 0.0000 & 0.3698 & 0.7116 & \multirow{8}{*}{-7.0635} & \multirow{8}{*}{-7.0438} & \multirow{8}{*}{-7.0564} \\
\hline & & $\varphi_{1}$ & 0.6094 & 0.0092 & 66.5553 & 0.0000 & & & \\
\hline & & $\varphi_{2}$ & 0.0852 & 0.0045 & 18.7897 & 0.0000 & & & \\
\hline & & $\theta_{1}$ & -0.6012 & 0.0038 & -159.8213 & 0.0000 & & & \\
\hline & & $\omega$ & -0.0960 & $2.3 \mathrm{e}^{-4}$ & -418.1551 & 0.0000 & & & \\
\hline & & $\alpha_{1}$ & -0.8581 & $1.05 \mathrm{e}^{-4}$ & -8158.1158 & 0.0000 & & & \\
\hline & & $\beta_{1}$ & 0.9903 & $8.6 e^{-5}$ & 11523.0226 & 0.0000 & & & \\
\hline & & $\gamma_{1}$ & 0.8591 & $1.05 \mathrm{e}^{-4}$ & 8183.2788 & 0.0000 & & & \\
\hline
\end{tabular}

\section{Conclusion}

Our study has shown that the use of minimum unconditional variance as a measure of efficiency of heteroscedastic models in the presence of outliers is not heuristic as outliers are capable of inflating or reducing the unconditional variance. To this end, the use of kurtosis coefficient as a measure of heteroscedastic 
Table 8. Diagnostic checking for ARIMA-GARCH-type models of outlier adjusted returns series of Nigerian Banks.

\begin{tabular}{|c|c|c|c|c|c|c|c|c|c|c|}
\hline \multirow{2}{*}{ Bank } & \multirow{2}{*}{ Model } & \multicolumn{3}{|c|}{ Standardized Residuals } & \multicolumn{6}{|c|}{ Standardized Squared Residuals } \\
\hline & & Lag & Weighted LB & $\mathrm{p}$-value & Lag & Weighted LB & $\mathrm{p}$-value & Lag & $\begin{array}{l}\text { Weighted } \\
\text { ARCH-LM }\end{array}$ & $\mathrm{p}$-value \\
\hline \multirow{3}{*}{ SKYE } & \multirow{3}{*}{$\begin{array}{c}\text { ARIMA }(1,1,0) \\
\text {-GARCH(1,1)-norm }\end{array}$} & 1 & 1.323 & 0.2500 & 1 & 2.227 & 0.1356 & 3 & 1.113 & 0.2914 \\
\hline & & 2 & 2.710 & 0.0617 & 5 & 3.072 & 0.3941 & 5 & 1.375 & 0.6257 \\
\hline & & 5 & 4.284 & 0.1838 & 9 & 3.533 & 0.6687 & 7 & 1.472 & 0.8269 \\
\hline \multirow{3}{*}{ STERLING } & \multirow{3}{*}{$\begin{array}{c}\operatorname{ARIMA}(2,1,2) \\
-\operatorname{EGARCH}(1,1)-\text { std }\end{array}$} & 1 & 0.0014 & 0.9707 & 1 & 0.0013 & 0.9716 & 3 & 0.0013 & 0.9716 \\
\hline & & 11 & 0.0087 & 1.0000 & 5 & 0.0038 & 1.0000 & 5 & 0.0030 & 0.9999 \\
\hline & & 19 & 0.0145 & 1.0000 & 9 & 0.0063 & 1.0000 & 7 & 0.0045 & 1.0000 \\
\hline \multirow{3}{*}{ UNITY } & \multirow{3}{*}{$\begin{array}{c}\operatorname{ARIMA}(1,1,0) \\
\text {-GJR-GARCH( }(1,0) \\
\text {-norm }\end{array}$} & 1 & 0.0081 & 0.9283 & 1 & 0.3091 & 0.5782 & 2 & 0.0990 & 0.7530 \\
\hline & & 2 & 0.0158 & 1.0000 & 2 & 0.3587 & 0.7639 & 4 & 2.5450 & 0.3332 \\
\hline & & 5 & 4.3656 & 0.1730 & 5 & 2.3489 & 0.5386 & 6 & 2.8354 & 0.5386 \\
\hline \multirow{3}{*}{ ZENITH } & \multirow{3}{*}{$\begin{array}{c}\operatorname{ARIMA}(2,1,1) \\
-\operatorname{EGARCH}(1,1)-\text { std }\end{array}$} & 1 & 0.0010 & 0.9752 & 1 & 0.0009 & 0.9756 & 3 & 0.0009 & 0.9756 \\
\hline & & 8 & 0.0058 & 1.0000 & 5 & 0.0028 & 1.0000 & 5 & 0.0022 & 0.9999 \\
\hline & & 14 & 0.0100 & 1.0000 & 9 & 0.0047 & 1.0000 & 7 & 0.0033 & 1.0000 \\
\hline
\end{tabular}

LB = Ljung-Box, $\mathrm{LM}=$ Lagrange Multiplier.

Table 9. Efficiency of ARIMA-GARCH-type model of Skye Bank.

\begin{tabular}{ccc}
\hline Efficiency Measurement Criteria & $\begin{array}{c}\text { ARIMA(1,1,0)-GARCH(1,1)-norm Model } \\
\text { fitted to Returns Series of Skye Bank }\end{array}$ & $\begin{array}{c}\text { ARIMA(1,1,0)-GARCH(1,1)-norm Model fitted to } \\
\text { Outlier Adjusted Return Series of Skye Bank }\end{array}$ \\
\hline Unconditional Variance & 0.0016 & 0.0016 \\
Kurtosis Coefficient & 132.8707 & 2.9465 \\
\hline
\end{tabular}

Table 10. Efficiency of ARIMA-GARCH-type model of Sterling Bank.

\begin{tabular}{ccc}
\hline Efficiency Measurement Criteria & $\begin{array}{c}\text { ARIMA(2,1,0)-EGARCH(1,1)-norm Model fitted } \\
\text { to Returns Series of Sterling Bank }\end{array}$ & $\begin{array}{c}\text { ARIMA(2,1,2)-EGARCH(1,1)-std Model fitted to } \\
\text { Outlier Adjusted Return Series of Sterling Bank }\end{array}$ \\
\hline Unconditional Variance & 0.0012288 & $4.234715 \mathrm{e}^{-6}$ \\
Kurtosis Coefficient & 80.0303 & 3.6829 \\
\hline
\end{tabular}

Table 11. Efficiency of ARIMA-GARCH-type model of Unity Bank.

\begin{tabular}{ccc}
\hline Efficiency Measurement Criteria & $\begin{array}{c}\text { ARIMA(0,1,1)-GARCH (1,1)-norm Model fitted to } \\
\text { Returns Series of Unity Bank }\end{array}$ & $\begin{array}{c}\text { ARIMA(1,1,0) -GJR-GARCH(1,0)-norm Model fitted } \\
\text { to Outlier Adjusted Return Series of Unity Bank }\end{array}$ \\
\hline Unconditional Variance & 0.0037 & $2.104825 \mathrm{e}^{-5}$ \\
Kurtosis Coefficient & 888.5032 & 3.2678 \\
\hline
\end{tabular}

Table 12. Efficiency of ARIMA-GARCH-type model of Zenith Bank.

\begin{tabular}{ccc}
\hline Efficiency Measurement Criteria & $\begin{array}{c}\text { ARIMA(2,1,1)-EGARCH(1,1)-std Model fitted to } \\
\text { Returns Series of Zenith Bank }\end{array}$ & $\begin{array}{c}\text { ARIMA(2,1,1)-EGARCH(1,1)-std Model fitted to } \\
\text { Outlier Adjusted Return Series of Zenith Bank }\end{array}$ \\
\hline Unconditional Variance & $5.887684 \mathrm{e}^{-36}$ & $5.118125 \mathrm{e}^{-5}$ \\
Kurtosis Coefficient & 26.3794 & 3.5746 \\
\hline
\end{tabular}


models in the presence of outliers becomes more tractable irrespective of the choice of distribution of the innovations. In addition, this study highlights that the applicability of iterative methods in time series modeling and in gauging model efficiency yet failed to consider the application of iterative methods in forecasting. It is recommended that further studies be extended to focus mainly on the application of iterative methods in maximum likelihood estimation of GARCH parameters.

\section{Conflicts of Interest}

The authors declare no conflicts of interest regarding the publication of this paper.

\section{References}

[1] Engle, R.F. and Ng, V.K. (1993) Measuring and Testing the Impact of News on Volatility. Journal of Finance, 48, 1749-1778. https://doi.org/10.1111/j.1540-6261.1993.tb05127.x

[2] Francq, C. and Zakoian, J. (2010) GARCH Models: Structure, Statistical Inference and Financial Applications. 1st Edition, John Wiley \& Sons Ltd., Chichester, 19-220. https://doi.org/10.1002/9780470670057

[3] Moffat, I.U. and Akpan, E.A. (2018) Modeling Heteroscedasticity of Discrete-Time Series in the Face of Excess Kurtosis. Global Journal of Science Frontier Research: F Mathematics and Decision Sciences, 18, 23-32.

[4] Feng, L. and Shi, Y. (2017) A Simulation Study on the Distributions of Disturbances in GARCH Model. Cogent Economics and Finance, 5, Article ID: 1355503. https://doi.org/10.1080/23322039.2017.1355503

[5] Cain, M.K., Zhang, Z. and Yuan, K. (2017) Univariate and Multivariate Skewness and Kurtosis for Measuring Nonnormality: Prevalence Influence and Estimation. Behavior Research Methods, 49, 1716-1735. https://doi.org/10.3758/s13428-016-0814-1

[6] Fiori, A.M. and Beltrami, D. (2014) Right and Left Kurtosis Measures: Large Sample Estimation and an Application to Financial Returns. STAT, 3, 95-108. https://doi.org/10.1002/sta4.48

[7] Westfall, P. H. (2014) Kurtosis as Peakness, 1905-2014. R.I.P. The American Statistician, 68, 191-195. https://doi.org/10.1080/00031305.2014.917055

[8] Akpan, E.A., Lasisi, K.E and Adamu, A. (2018) Modeling Heteroscedasticity in the Presence of Outliers in Discrete-Time Stochastic Series. Academic Journal of Applied Mathematical Sciences, 4, 61-76.

[9] Akpan, E.A. and Moffat, I.U. (2017) Detection and Modeling of Asymmetric GARCH Effects in a Discrete-Time Series. International Journal of Statistics and Probability, 6, 111-119. https://doi.org/10.5539/ijsp.v6n6p111

[10] Box, G.E.P., Jenkins, G.M. and Reinsel, G.C. (2008) Time Series Analysis: Forecasting and Control. 3rd Edition, John Wiley \& Sons, Hoboken, NJ, 5-22. https://doi.org/10.1002/9781118619193

[11] Engle, R.F. (1982) Autoregressive Conditional Heteroscedasticity with Estimates of the Variance of United Kingdom Inflations. Econometrica, 50, 987-1007. https://doi.org/10.2307/1912773

[12] Bollerslev, T. (1986) Generalized Autoregressive Conditional Heteroscedasticity. 
Journal of Econometrics, 31, 307-327.

https://doi.org/10.1016/0304-4076(86)90063-1

[13] Tsay, R.S. (2010) Analysis of Financial Time Series. 3rd Edition, John Wiley \& Sons Inc., New York, 97-140. https://doi.org/10.1002/9780470644560

[14] Nelson, D.B. (1991) Conditional Heteroscedasticity of Asset Returns. A New Approach. Econometrica, 59, 347-370. https://doi.org/10.2307/2938260

[15] Glosten, L.R., Jagannathan, R. and Runkle, D. (1993) On the Relation between the expected Values and the Volatility of the Nominal Excess Return on Stocks. Journal of Finance, 48, 1779-1801. https://doi.org/10.1111/j.1540-6261.1993.tb05128.x

[16] Moffat, I.U. and Akpan, E.A. (2017) Identification and Modeling of Outliers in a Discrete-Time Stochastic Series. American Journal of Theoretical and Applied Statistics, 6, 191-197. https://doi.org/10.11648/j.ajtas.20170604.14

[17] Sanchez, M.J. and Pena, D. (2003) The Identification of Multiple Outliers in ARIMA Models. Communications in Statistics-Theory and Methods, 32, 1265-1287. https://doi.org/10.1081/STA-120021331

[18] Wei, W.W.S. (2006) Time Series Analysis Univariate and Multivariate Methods. 2nd Edition, Addison-Wesley, New York, 3-59.

[19] Chen, C. and Liu, L.M. (1993) Joint Estimation of Model Parameters and Outlier Effects in Time Series. Journal of the American Statistical Association, 8, 284-297.

[20] Chang, I., Tiao, G.C. and Chen, C. (1988) Estimation of Time Series Parameters in the Presence of Outliers. Technometrics, 30, 193-204. https://doi.org/10.1080/00401706.1988.10488367

[21] Carnero, M.A., Pena, D and Ruiz, E. (2012) Estimating GARCH Volatility in the Presence of Outliers. Economics Letters, 114, 86-90.

https://doi.org/10.1016/j.econlet.2011.09.023 